\title{
Diffusion Model for the Adoption of Smartphone Brands under Competitive Pricing
}

\author{
Rashini Ashokan, Gabriel Lopez Zenarosa, and Xiuli He
}

\begin{abstract}
We extend the Bass diffusion model to capture the dynamic adoption and competitive pricing of two smartphone brands: Apple and Samsung. We use publicly available historical data to regress the model parameters. We find our model to reasonably fit the data, and we provide some insights on the competition between the smartphones brands with respect to our model and the available data.
\end{abstract}

Index Terms-Adoption, competition, pricing, smartphone.

\section{INTRODUCTION}

The Bass diffusion model [1], henceforth referred to as Bass Model, is one of the most influential models in marketing used to describe the diffusion process of adoption of a wide class of products and services by consumers [2]. The Bass Model enables realistic predictions on sales growth patterns and peaks of marketed products and services, as it accounts for saturation effects. Formally, the Bass Model is formulated for discrete time periods $t \geq 1$ as:

$$
S_{t}^{B}=m p+(q-p) Y_{t-1}-\frac{q}{m} Y_{t-1}^{2}
$$

where

$S_{t}^{B}$ is the adoption (i.e., product sales) at time $t \geq 1$;

$m$ is the total market potential;

$p$ is the fraction of the market that adopt the product early and are known as innovators [3];

$q$ is the fraction of the market that adopt the product after the innovators and are known as imitators [3], and;

$Y_{t-1}=\sum_{\tau=1}^{t-1} S_{\tau}^{B}$ is the cumulative adoption at time $t-1$ and $Y_{t-1}^{2}$ is its squared value.

Many extensions to the Bass Model have been surveyed (cf. [4]-[6]), where the extended models capture additional parameters of the adoption dynamics specific to the studied product or service. An extension of the Bass Model of interest in the current study is one by Gutierrez and $\mathrm{He}$ [7], henceforth referred to as Gutierrez-He Model, which

Manuscript received March 6, 2018; revised May 15, 2018. This work was supported in part by U.S. Air Force Research Laboratory Summer Faculty Fellowship Program.

R. Ashokan graduated with an MS in Engineering Management from the University of North Carolina at Charlotte, Charlotte, NC 28223 USA (e-mail: rashokan@uncc.edu).

G. L. Zenarosa is with the Systems Engineering and Engineering Management Department, University of North Carolina, Charlotte, NC 28223 USA (e-mail: gabriel.zenarosa@uncc.edu).

$\mathrm{X}$. $\mathrm{He}$ is with the Business Information Systems \& Operations Management Department, University of North Carolina, Charlotte, NC 28223 USA (e-mail: xhe8@uncc.edu). accounts for the effects of the time-varying price of the product within the diffusion process. Formally, their model is formulated for discrete time periods $t \geq 1$ as:

$$
S_{t}^{G H}=\left[p m+(q-p) Y_{t-1}-\left(\frac{q}{m}\right) Y_{t-1}^{2}\right]\left(1-\gamma R_{t}\right),
$$

where

$S_{t}^{G H}$ is the adoption at time $t \geq 1$;

$m$ is the total market potential;

$p$ is the fraction of the market that are innovators;

$q$ is the fraction of the market that are imitators;

$Y_{t-1}=\sum_{\tau=1}^{t-1} S_{\tau}^{G H}$ is the cumulative adoption at time $t-1$;

$\gamma$ is the consumer sensitivity to the retail price, and;

$R_{t}$ is the average retail price of the marketed product at time $t$.

Thus, a change in price of the marketed product induces a change in the predicted adoption by a factor of $-\gamma$.

In this paper, we present our extension of the Gutierrez-He Model that captures the dynamic sales and pricing between two competing brands of products. More specific, we use our model to analyze the diffusion process of adoption as influenced by the average pricing of Apple and Samsung brands of smartphones. We use publicly available historical data from the vendors' quarterly earnings reports along with third-party data of smartphone market-shares to regress the parameters to our model. We provide some insights on the competition between Apple and Samsung smartphones with respect to our model and the available data.

The rest of the paper is organized as follows. We formally describe our model and methods for analysis in Section II. We present the results of our analysis in Section III. We provide a discussion in Section IV. Finally, we summarize this paper in Section V.

\section{METHODS}

\section{A. Extended Model}

We extend the Gutierrez-He Model by accounting for the retail price of a competing product in the prediction of sales. Our diffusion model for product adoption under competitive pricing is formally formulated for discrete time $t \geq 1$ as:

$$
\begin{array}{r}
S_{t}^{A Z H}=\left[p m+(q-p) Y_{t-1}-\left(\frac{q}{m}\right) Y_{t-1}^{2}\right] . \\
{\left[1-\gamma\left(R_{t}-Q_{t}\right)\right],}
\end{array}
$$

where 
$S_{t}^{A Z H}$ is the adoption at time $t \geq 1$;

$m$ is the total market potential;

$p$ is the fraction of the market that are innovators;

$q$ is the fraction of the market that are imitators;

$Y_{t-1}=\sum_{\tau=1}^{t-1} S_{\tau}^{A Z H}$ is the cumulative adoption at time $t-1$;

$\gamma$ is the consumers' sensitivity to the product price;

$R_{t}$ is the average retail price of the marketed product at time $t$, and;

$Q_{t}$ is the average retail price of the competing product at time $t$.

Thus, similar to Gutierrez and He [7], a change in the price difference between the marketed and competing products induces a change in the predicted adoption by a factor of $-\gamma$.

\section{B. Data Sources}

We used publicly accessible quarterly earnings reports of Apple [8] and Samsung [9] to obtain their revenues from smartphone sales world-wide. Quarterly Apple iPhone revenues are available from the third quarter of 2007 (i.e., when the original iPhone was released). Quarterly Samsung smartphone revenues are available only from the first quarter of 2010 (i.e., as back-referenced in the first available Samsung quarterly report for the first quarter of 2011), although Samsung's smartphone production history dates back to 2008 [10]. In the absence of historical Samsung smartphone revenue information, we assumed Samsung smartphone sales started in the first quarter of 2010 :

$$
Y_{(t-1)=(2010, Q 1)-1}=0 \text {. }
$$

We converted Samsung sales figures from South Korean Won (KRW) to US Dollars (USD) using historical currency exchange rates from a publicly accessible web service [11].

We used the Apple quarterly reports [8] to obtain the number of iPhones sold globally, which allowed for the calculation of the average iPhone retail price per quarter. Because the Samsung quarterly reports [9] do not include the number of smartphones sold, we used publicly accessible data [12] for the smartphone global market shares of both Apple and Samsung to estimate the missing information. We then derived the quarterly average retail price of Samsung smartphones using the smartphone revenues.

\section{Regression Setup}

We performed our regression analyses using $\mathrm{R}$ [13]. We used the nonlinear regression function $n l s()$ to find the parameters to the Bass and Gutierrez-He Models, as well as our model in the current study. We verified the function $\mathrm{nls}$ () to regress the same parameters obtained using the linear regression function $\operatorname{lm}($ ) for the Bass Model, which is linear in the coefficients.

\section{RESULTS}

The regressed parameters to the Bass and Gutierrez-He Models, as well as to our current study are shown in Table I. Across all models for the relevant timelines, the regressed average iPhone market potential lies between 1.6 million and 1.8 million customers (i.e., some being repeat customers), and the regressed average Samsung smartphone market potential ranges lies between 2.5 million and 2.6 million customers. The percentage of innovators for the iPhone market is $0.25 \%-0.71 \%$, while that for Samsung smartphone market is $0.79 \%-1.10 \%$. The percentage of imitators for the iPhone market is $9.15 \%-13.25 \%$, while that for the Samsung smartphone market is $9.03 \%-13.41 \%$. The adoption of Samsung smartphones is negatively impacted by increases in product pricing (i.e., at rate $-\gamma=0.000523$ ) and competitive pricing gap (i.e., at rate $-\gamma=0.000787$ ). The adoption of iPhones, however, is unaffected by product pricing (i.e., $\gamma=0$ ) and positively impacted by increases in competitive pricing gap (i.e., at rate $-\gamma=-0.000520$ ), which we discuss in the next section.

The corresponding plots for the nonlinear regression lines for (1), (2), and (3) along with the observed smartphone sales data points are shown in Fig. 1. We observe that Panels (a) and (c) in Fig. 1 are the same plots, which result from having regressed parameter $\gamma=0$ in the Gutierrez-He Model for iPhone, so that all other regressed parameters match those of the Bass Model for iPhone. We also observe that Panels (d) and (f) in Fig. 1 are similar (but not exact; cf. the different regression curves for observations at $t=30$, for example), which result from having regressed similar parameters for the Gutierrez-He Model and our model for Samsung smartphones.

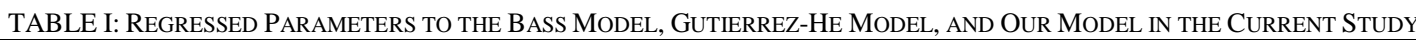

\begin{tabular}{|c|c|c|c|c|c|c|}
\hline \multirow[b]{2}{*}{ Parameter } & \multicolumn{2}{|c|}{ Bass Model } & \multicolumn{2}{|c|}{ Gutierrez-He Model } & \multicolumn{2}{|c|}{ Current Study } \\
\hline & iPhone & Samsung & iPhone & Samsung & iPhone & Samsung \\
\hline$m$ & $1,650.041 \times 10^{6}$ & $2,458.518 \times 10^{6}$ & $1,650.041 \times 10^{6}$ & $2,581.486 \times 10^{6}$ & $1,782.727 \times 10^{6}$ & $2,565.338 \times 10^{6}$ \\
\hline$p$ & 0.002493 & 0.007898 & 0.002493 & 0.016198 & 0.007083 & 0.011002 \\
\hline$q$ & 0.132501 & 0.134107 & 0.132501 & 0.134654 & 0.091516 & 0.090273 \\
\hline$\gamma$ & - & - & 0 & 0.000523 & -0.000520 & 0.000787 \\
\hline
\end{tabular}

\section{DisCUSSION}

The regression lines for the Bass and Gutierrez-He Models, as well as our model for the current study appear to fit the observed data relatively well. The $R^{2}$ values for quarterly Apple and Samsung smartphone unit sales under the Bass Model (i.e., a linear regression model) are 0.8364 and 0.6028 . Additionally, the correlation coefficients (i.e., inadequate statistics for nonlinear models if reported alone [14]) of the
Gutierrez-He Model and our model for the iPhone (i.e., 0.9145 and 0.8926 , respectively) and Samsung smartphones (i.e., 0.8637 and 0.8709 , respectively), along with a visual inspection of their respective regression lines in Fig. 1, indicate a reasonably good fit to the observed data.

We recall that the Gutierrez-He Model for the iPhone has regressed parameter $\gamma=0$ with the given data. An interpretation of this result is that iPhone sales are unaffected 
by their prices due to loyal customers and strong positive effects of word-of-mouth. This phenomenon can be informally observed from the heightened excitement of consumers whenever a new generation of iPhone products is announced and launched.

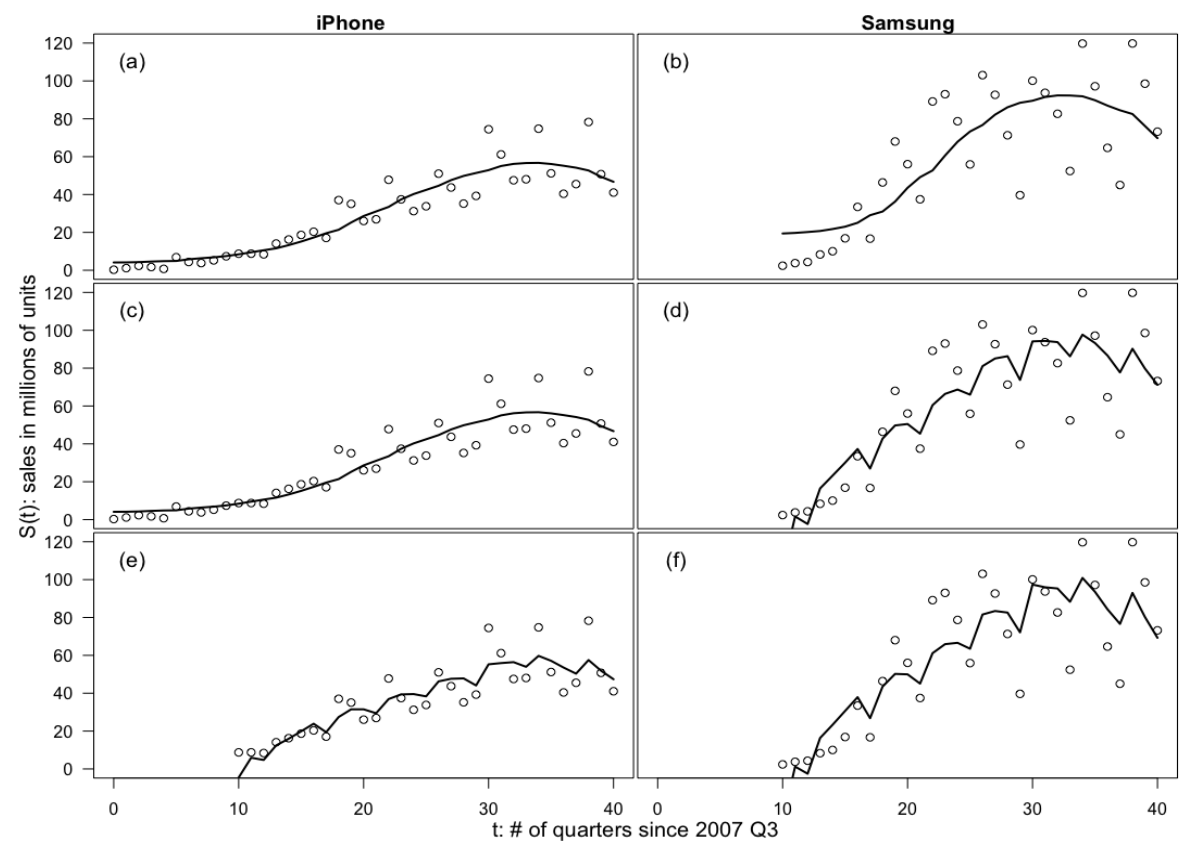

Fig. 1. Plots of the observed (i.e., circles $O$ ) and model-predicted (i.e., lines - ) quarterly iPhone and Samsung smartphone unit sales since the third quarter of 2007. Panels (a) and (b) are plots for the Bass Model; panels (c) and (d) are plots for the Gutierrez-He Model, and; panels (e) and (f) are plots for our model in the current study.

We also recall that our model for the iPhone has regressed a negative value for parameter $\gamma$ for the given data. This result indicates that increasing the price difference between the iPhone and Samsung smartphones leads to increasing iPhone adoption. While this result appears counterintuitive at first, it does support the iPhone customers' insensitivity to iPhone price increases without regard to competition (cf. the discussion above on regressed parameter $\gamma=0$ ). The positive impact of increasing the price difference between iPhone and Samsung smartphones may result from increasing the gap between the features and technologies used by the competing products. Further investigation of this finding is pending.

The diffusion models and analyses presented could be improved by incorporating additional information on the periodic release [15] of new generations of smartphones. We notice the wave-like patterns in the observed-data plots of Fig. 1 , which depict the rise, peak, and fall of generations of smartphones induced by their periodic release along with the corresponding product-substitution behavior of consumers (e.g., upgrading their current smartphone to latest generation or switching over to the latest competing smartphone). However, separable data on the generational release of smartphones are currently proprietary. Despite the unavailability of information, we find our model captures some of the generational release wave-like trends.

Additional data to supplement the incomplete information on unit sales and product pricing will also improve our regression analyses. Currently, we find the publicly accessible data on Samsung smartphone market share, which we used to estimate the number of smartphone units sold globally (i.e., separated from other mobile devices, such as tablets), are inconsistent with the iPhone market share-derived data. Additionally, the averaging of prices of overlapping releases of high-end (e.g., iPhone Plus) and low-end (e.g., iPhone 5C) smartphones may be problematic. Our search for supplemental data to enable more-accurate accounting and subsequent analyses is ongoing.

\section{CONCLUSION}

Our extension to the Bass Model and the Gutierrez-He Model captures the dynamic sales and competitive pricing of two smartphone brands: Apple and Samsung. We used publicly available historical data to regress the model parameters. Some of the regressed parameters, particularly the pricing-sensitivity parameter $\gamma$ for different models, were initially surprising but had reasonable interpretations. We discussed the relatively good fit of the models to the data, but provided ideas for improvement.

\section{ACKNOWLEDGMENT}

The authors are grateful to the anonymous reviewers for their comments on earlier version of this article. The U.S. Government is authorized to reproduce and distribute reprints for Governmental purposes notwithstanding any copyright notation thereon. The views and conclusions contained herein are those of the authors and should not be interpreted as necessarily representing the official policies or endorsements, either expressed or implied, of AFRL/RW or the U.S. Government.

\section{REFERENCES}

[1] F. M. Bass, "A new product growth for model consumer durables," Management Science, vol. 15, no. 5, pp. 215-227, January 1969.

[2] F. M. Bass, "Comments on 'A new product growth for model consumer durables," Management Science, vol. 50, no. 12, pp. 1833-1840, December 2004.

[3] E. M. Rogers, Diffusion of Innovation, 5th ed. The Free Press, 2003. 
[4] V. Mahajan, E. Muller, and F. M. Bass, "Diffusion of new products: Empirical generalizations and managerial uses," Marketing Science, vol. 14, no. 3 supplement, pp. G79-G88, August 1995.

[5] R. Peres, E. Muller, and V. Mahajan, "Innovation diffusion and new product growth models: A critical review and research directions," International Journal of Research in Marketing, vol. 27, no. 2, pp. 91-106, June 2010.

[6] T. Fan, P. N. Golder, and D. R. Lehmann, "Innovation and new products research: A state-of-the-art review, models for managerial decision making, and future research directions," Handbook of Marketing Decision Models, pp. 79-116, 2017.

[7] G. J. Gutierrez and X. He, "Life-cycle channel coordination issues in launching an innovative durable product," Production and Operations Management, vol. 20, no. 2 pp. 268-279, March-April 2011.

[8] Apple Inc., Cupertino, CA. Apple Inc. Earnings Releases and 10-K Annual Reports. [Online]. Available: http://investor.apple.com/financials.cfm

[9] Samsung Group, Seoul, South Korea. Samsung Electronics Earnings Releases. [Online]. Available: http://www.samsung.com/global/ir/financial-information/earnings-rel ease/

[10] S. Segan. (March 12, 2013). Samsung's Smartphone History: From Zero to Galaxy S4. PC Magazine. [Online]. Available: https://www.pcmag.com/feature/309047/samsung-s-smartphone-histo ry-from-zero-to-galaxy-s4

[11] X-Rates.com. US Dollar per 1 South Korean Won Monthly Average. [Online]. Available: http://www.X-rates.com/average/?from=KRW\&to=USD\&amount=1

[12] Statista Inc., Hamburg, Germany. Global Market Share Held by Leading Smartphone Vendors from 4th Quarter 2009 to 3rd Quarter $2017 . \quad$ [Online]. Available: https://www.statista.com/statistics/271496/global-market-share-held-b y-smartphone-vendors-since-4th-quarter-2009/

[13] R Foundation for Statistical Computing, Vienna, Austria. A Language and Environment for Statistical Computing. Online]. Available: https://www.R-project.org

[14] A.-N. Spiess and N. Neumeyer, "An Evaluation of $R^{2}$ as an Inadequate Measure for Nonlinear Models in Pharmacological and Biochemical Research: A Monte Carlo Approach," BMC Pharmacology, vol. 10, no. 6, pp. 1-11, June 2010.

[15] J. A. Norton and F. M. Bass, "A diffusion theory model of adoption and substitution for successive generations of high-technology products," Management Science, vol. 33, no. 9, pp. 1069-1086, September 1987.

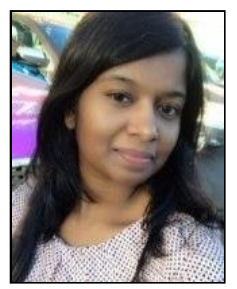

Rashini Ashokan obtained her MS in engineering management with a concentration in Lean Six Sigma from UNC Charlotte in 2017 and BS in electronics and communications engineering from SRM university at Chennai in 2012.

She worked as a software developer at Tata Consultancy Services, team leader at TechSet Composition Pvt. Ltd., business manager at Ace Coaching Center, graduate teaching assistant at UNC
Charlotte and Intern at XPO Logistics. Her research interests include lean logistics and supply chains.

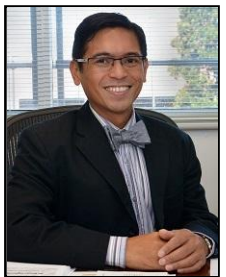

Gabriel Lopez Zenarosa obtained his $\mathrm{PhD}$ in industrial engineering from the University of Pittsburgh in 2016, Master of Software Engineering from Carnegie Mellon University in 2005, MS in computer science from Columbia University in 2002 and BS in computer science from the University of the Philippines in 1997.

$\mathrm{He}$ is currently an assistant professor of systems engineering and engineering management at UNC Charlotte. He was awarded an Air Force Research Laboratory (AFRL) Summer Faculty Fellowship in 2017. He was previously a software quality assurance test engineer at the University of Pittsburgh National Surgical Adjuvant Breast and Bowel Project (NSABP), a Software Process Consultant, a client support engineer at Nyfix, and a software development consultant. His research interests include stochastic optimization, chance-constrained programming, and computational optimization.

Dr. Zenarosa is a member of INFORMS, SIAM, ACM, and ISPOR.

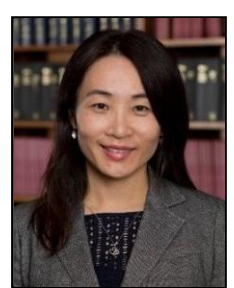

Xiuli He obtained her Ph.D. in operations and supply chain management from the University of Texas at Austin in 2007, MS in management science from Shanghai Jiao Tong University in 1999, and BE in mechanical engineering from Shanghai Tie Dao University in 1996.

She is currently an associate professor of operations management at UNC Charlotte Belk College of Business. Before joining the Belk College in 2008, she was a visiting assistant professor of operations management at the University of Texas at Dallas. Her work has been widely published in the leading academic journals. Her research interests include supply chain management, supply chain contracts, production cost learning, and dynamic pricing and advertising.

Dr. He serves as an associate editor for OMEGA and is on the editorial board of Production and Operations Management. She also served as an associate editor for International Journal of Production Research. 